\title{
Pengaruh Kerusakan Buah Kelapa Sawit terhadap Kandungan Free Fatty Acid dan Rendemen CPO di Kebun Talisayan 1 Berau
}

\section{The Effect of Palm Oil Fruit Bunch Injury to Free Fatty Acid Content and CPO Rendement at Talisayan 1 Estate Berau}

\section{Pryo Adi Lukito dan Sudradjat*}

Departemen Agronomi dan Hortikultura, Fakultas Pertanian, Institut Pertanian Bogor (Bogor Agricultural University), Jl. Meranti, Kampus IPB Darmaga, Bogor 16680, Indonesia Telp.\&Faks.62-251-8629353 e-mail agronipb@indo.net.id

"Penulis untuk korespondensi : sudradjat@yahoo.co.id

Disetujui 16 Januari 2017/Published online 24 Januari 2017

\begin{abstract}
The objective of this research specifically was to study the factors that affect the quality of CPO. The internship was conducted in Talisayan 1 Estate, Berau, East Kalimantan from February to June 2013. Problem analysis using Ishikawa diagram and linear regression by making poor quality fruit, fruit "restan" (leftover), injury fruit, and the loss of crops as factors that cause of problems. The analysis show that CPO degradation probelms one of which can be seen from the low rendement of palm oil (CPO) and high Free Fatty Acid (FFA) CPO. Low oil rendement caused by poor fruit quality and yield loss. High FFA CPO caused by poor quality fruit, leftover fruit, and fruit injury.
\end{abstract}

Keywords : CPO, FFA, harvest, palm oil, rendement

\section{ABSTRAK}

Kegiatan penelitian ini secara khusus bertujuan untuk memperlajari faktor-faktor yang mempengaruhi mutu CPO yang dilaksanakan di Kebun Talisayan 1, Berau, Kalimantan Timur dari bulan Februari sampai Juni 2013. Analisis data dan masalah menggunakan diagram Ishikawa dan regresi linier. Faktor-faktor yang memperngaruhi mutu CPO adalah buah bermutu buruk, buah terlambat pengangkutan (restan), buah luka, dan kehilangan hasil panen. Hasil analisis menunjukkan bahwa masalah penurunan mutu CPO disebabkan oleh rendahnya rendemen minyak kelapa sawit (CPO) dan tingginya kandungan Free Fatty Acid (FFA) dalam CPO. Rendemen minyak yang rendah karena mutu buah yang buruk dan kehilangan hasil panen. Kandungan FFA CPO tinggi karena mutu buah buruk, buah restan (terlambat pengangkutan), dan buah luka.

Kata kunci : CPO, FFA, kelapa sawit, panen, rendemen 


\section{PENDAHULUAN}

Indonesia adalah negara dengan luas perkebunan kelapa sawit dan sebagai produsen Crude Palm Oil (CPO) nomor satu di dunia, yakni sekitar 24 juta ton (Wahyudi 2012). Produksi CPO Indonesia selain menjadisumber pendapatan negara,juga sekaligus memenuhi $47 \%$ kebutuhan minyak nabati dunia (Wiyono 2013). Manfaat lain dari adanya perkebunan kelapa sawit yaitu terbukanya lapangan pekerjaan baru bagi masyarakat yang hidup di sekitar perkebunan, yang diharapkan dapat mendongkrak perekonomian dan taraf hidup masyarakat secara berkelanjutan.

Tantangan Indonesia saat ini adalah menjaga kepercayaan konsumen CPO dari isu-isu negatiftentang kelapasawit yang sedang berkembang dengan cara tetap memproduksi CPO yang bermutu dan bersertifikat secara nasional dan internasional. Indonesia juga harus dapat terus bersaing di pasar minyak nabati dunia bersama nagara produsen lainya seperti Malaysia; memenuhi kebutuhan dalam negeri; serta meningkatkan pertumbuhan perekonomian negara.

Mutu CPO dapat dilihat secara kuantitas dan kualitas. Produksi buah dengan kuantitas baik akan menghasilkan rendemen CPO 23.2-27.4\% (Pahan 2006) dengan kadar asam lemak bebas (ALB) atau Free Fatty Acid (FFA) < 3\% (Mangoensoekarjo dan Semangun 2003). Rendemen minyak yang tinggi didapatkan dengan cara mengolah buah kelapa sawit yang matang (ripe), karena buah yang matang memiliki kandungan minyak terbanyak (rendemen minyak tinggi) daripada jenis atau kelompok mutu buah lainnya. Buah matang diperoleh dari kegiatan panen atau potong buah sehingga mengharuskan pemanen untuk mengutamakan momotong buah matang dengan jumlah paling banyak (> 98\%) agar hasil ekstraksi minyak (rendemen CPO) tinggi.

Semakin tinggi kandungan FFA, maka semakin rendah kualitas CPO. Pengaruh rendah atau tingginya FFA dan rendemenCPO terletak pada mutu buah yang dipanen. Mutu buah yang baik akan menghasilkan CPO dengan FFA rendah dan rendemen minyak yang tinggi. Buah yang terlambat diolah akibat terlambat pengangkutan(restan) dapat meningkatkan FFA, selain itu penanganan yang kasar juga dapat meningkatkan laju FFA. Luka pada buah kelapa sawit akibat penanganan yang kasar dapat menstimulasi konversi molekul minyak menjadi FFA dengan laju yang sangat tinggi, sehingga kandungan FFA meningkat dengan cepat (Mangoensoekarjo dan Semangun 2003).

Pembentukan FFA terbanyak adalah saat di lapangan atau sebelum mulai diolah di Pabrik Kelapa Sawit (PKS), karena pada saat pengolahan di PKS kenaikan FFA hanya $0.1 \%$ atau paling tinggi $0.3-0.5 \%$ pada PKS yang kurang terkendali pengawasannya. Kenaikan FFA saat penimbunan dan pengapalan hingga sampai di tangan konsumen juga relatif rendah (Mangoensoekarjo dan Semangun 2003).

Tujuan utama kegiatan penelitian adalah memperlajari kegiatan pada semua jenjang karier di perkebunan kelapa sawit serta memperkaya pengalaman kerja di perusahaan kelapa sawit baik aspek teknis maupun manajerial. Secara khusus penelitian ini bertujuan mempelajari faktor-faktor yang mempengaruhi mutu CPO dalam kegiatan perkebunan kelapa sawit.

\section{METODE PENELITIAN}

Pelaksanaan penelitian dimulai pada 11 Februari hingga 11 Juni 2013 bertempat di Kebun Talisayan 1, Desa Cepuak, Kecamatan Talisayan, Kabupaten Berau, Kalimantan Timur. Observasi lapangan bertujuan mengumpulkan informasi secara langsung di lapangan baik dengan cara pengamatan maupun wawancara. Observasi lapangan yang dilakukan meliputi: (1) penentuan masalah produksi buah atau tandan buah segar (TBS) yang bermutu buruk; (2) pengumpulan dan penyusunan buah di tempat pengumpulan hasil (TPH) yang kurang disiplin; (3) pengangkutan buah dari TPH ke pabrik kelapa sawit (PKS) yang kurang efektif. Ketiga pokok masalah tersebut diidentifikasi menggunakan diagram Ishikawa sehingga dapat ditentukan akar permasalahan hasil observasi.

Peubah untuk mengamati mutu CPO terdiri dari: (1) buah lepas berumur restan (keterlambatan angkut) 0-14 hari dengan masingmasing umur restan diambil sebanyak 50 gram;(2) data sekunder perusahaan, diantaranya hasil grading mutu buah buah di PKS; rendemen CPO; dan kadar FFA CPO harian. Contoh buah lepas dengan berbagai umur restan digunakan untuk uji laboratorium kandungan FFA dalam CPO setiap umur restan (0-14 hari).

Pengambilan contoh buah lepas dilakukan sekaligus untuk kebutuhan 14 hari pangamatan pada blok sesuai jadwal panen. Buah lepas kemudian diseleksi dengan cara melihat bagian buah yang menempel pada spikelet (pangkal buah) satu persatu dan dipilih yang masih segar atau berwarna putih. Kriteria pangkal buah lepas yang masih segar dan berwarna putih mencirikan 
umur buah lepas yang baru saja lepas dari tandannya $(<1$ hari), sehingga diasumsikan umur buah lepas seragam. Umur restan buatan 0-14 hari dilakukan oleh penulis dengan cara menyimpan buah lepas terseleksi di tempat terbuka dengan penagawasan penulis agar tidak hilang atau rusak karena hewan liar di sekitar kebun, selama 14 hari. Buah lepas terseleksi setiap hari dianalisis kandungan FFAnya dengan ulangan sebanyak tiga kali.

Data-data sekunder perusahaan digunakan untuk mengukur besaran dampak suatu masalah melalui analisis regresi linear sederhana.Pengujian di laboratorium untuk mengetahui kadar FFA pada buah restan dengan berbagai umur restan. Analisis FFA dilakukan sesuai dengan prosedur yang dilakukan di perusahaan yaitu dengan metode titrasi. Perhitungan FFA adalah sebagai berikut:

$$
\text { FFA }(\%)=\frac{25.6 \times \text { Normalitas } \mathrm{NaOH} \times \text { Vol. titrasi } \mathrm{NaOH}}{\text { gram sampel CPO }}
$$

Pengukuran dampak atau risiko kandungan FFAdalam CPO yang tinggi dan rendemen CPO yang rendah menggunakan analisis regresi linear sederhana dan uji nilai signifikasi. Analisis regresi data dan informasi dilakukan dengan bantuan perangkat lunak Microsoft Office Excel 2007 dan MINITAB 1.4.

\section{HASIL DAN PEMBAHASAN}

\section{Kenaikan FFA dalam CPO karena Dampak Mutu Buah}

Mutu buah yang dipanen dapat diketahui dengan cara grading buah. Hasil grading mengelompokkan buah bermutu buruk adalah buah mentah (unripe), buah lewat matang (over ripe), buah busuk dan atau janjang kosong (empty bunch), serta buah abnormal. Pengujian dilakukan pada setiap kelompok mutu buah tersebut untuk menduga dampak kenaikan kandungan Free Fatty Acid (FFA) dalam CPO. Hubungan antara produksi buah bermutu buruk dengan kandungan FFA dalam CPO dapat dilihat pada Tabel 1.

Tabel 1. Hubungan persentase produksibuah bermutu buruk (buah mentah, buah lewat matang, janjang kosong dan buah busuk, serta buah abnormal) bulanan dengan rataan kandungan FFA dalam CPO pada Januari 2012-April 2013

\begin{tabular}{lccccc}
\hline \multicolumn{1}{c}{ Bulan } & BM $(\%)$ & BLM $(\%)$ & JJK $(\%)$ & Abnormal $(\%)$ & FFA $(\%)$ \\
\hline Januari 12 & $3.85 \pm 1.76$ & $15.56 \pm 5.98$ & $1.11 \pm 0.99$ & $9.15 \pm 2.10$ & $2.71 \pm 0.28$ \\
Februari 12 & $5.01 \pm 1.67$ & $17.24 \pm 5.77$ & $1.10 \pm 0.73$ & $9.37 \pm 2.90$ & $2.61 \pm 0.22$ \\
Maret 12 & $2.95 \pm 1.63$ & $28.89 \pm 11.42$ & $4.69 \pm 4.25$ & $9.22 \pm 2.63$ & $2.78 \pm 0.24$ \\
April 12 & $5.17 \pm 2.03$ & $19.81 \pm 6.65$ & $3.06 \pm 3.63$ & $10.89 \pm 3.77$ & $2.72 \pm 0.17$ \\
Mei 12 & $6.87 \pm 2.36$ & $14.02 \pm 5.74$ & $2.02 \pm 2.68$ & $14.97 \pm 5.27$ & $3.18 \pm 0.25$ \\
Juni 12 & $6.04 \pm 2.91$ & $8.44 \pm 4.12$ & $0.87 \pm 0.70$ & $17.99 \pm 8.51$ & $4.94 \pm 2.52$ \\
Juli 12 & $5.34 \pm 2.31$ & $7.60 \pm 3.19$ & $0.92 \pm 0.61$ & $24.80 \pm 11.63$ & $3.58 \pm 0.16$ \\
Agustus 12 & $1.78 \pm 19.3$ & $6.18 \pm 4.47$ & $1.21 \pm 1.01$ & $23.52 \pm 0.59$ & $3.89 \pm 0.13$ \\
Septemeber 12 & $5.00 \pm 2.65$ & $13.35 \pm 7.48$ & $4.30 \pm 3.49$ & $29.26 \pm 14.88$ & $3.97 \pm 0.02$ \\
Oktober 12 & $6.37 \pm 3.22$ & $6.33 \pm 3.40$ & $1.04 \pm 0.64$ & $27.11 \pm 13.16$ & $2.97 \pm 0.36$ \\
November 12 & $4.04 \pm 2.09$ & $9.36 \pm 5.35$ & $2.32 \pm 1.58$ & $18.81 \pm 10.04$ & $3.01 \pm 0.22$ \\
Desember 12 & $5.44 \pm 2.94$ & $12.68 \pm 6.95$ & $2.61 \pm 2.01$ & $15.79 \pm 9.23$ & $2.89 \pm 0.07$ \\
Januari 13 & $4.49 \pm 2.69$ & $17.62 \pm 10.43$ & $5.11 \pm 4.77$ & $12.45 \pm 8.60$ & $2.95 \pm 0.09$ \\
Februari 13 & $4.03 \pm 2.71$ & $16.83 \pm 11.99$ & $7.68 \pm 7.64$ & $9.72 \pm 8.42$ & $3.67 \pm 0.23$ \\
Maret 13 & $4.37 \pm 2.95$ & $15.09 \pm 9.65$ & $7.20 \pm 6.72$ & $8.92 \pm 8.05$ & $3.61 \pm 0.32$ \\
April 13 & $5.93 \pm 3.57$ & $15.80 \pm 8.01$ & $4.88 \pm 4.61$ & $9.25 \pm 4.50$ & $2.94 \pm 0.08$ \\
\hline Persan
\end{tabular}

Persamaan regresi linier FFA $(\%)=3.26-0.08 \mathrm{BM}-0.04 \mathrm{BLM}+0.13 \mathrm{JJK}+0.03$ abnormal $\mathrm{R}^{2}$ $69.1 \%$

Sumber : Laboratorium Talisayan Mill (TSM)

Keterangan : BM (buah mentah), BLM (buah lewat matang), JJK (janjang kosong dan buah busuk) 
Mutu buah yang buruk dapat meningkatkan kadar FFA secara signifikan saat buah tersebut diolah menjadi CPO secara bersamaan. Berdasarkan prediksi persamaan regresi linier (Tabel 1) kadar FFA dalam CPO akan meningkat sebesar $0.04 \%$ setiap pengolahan $1 \%$ buah buah bermutu buruk.

Peneletian sebelumnya dilakukan oleh Djoharet al. (2003) dengan menghasilkan kesimpulan bahwa pengolahan buah busuk 1\% akan meningkatkan kandungan FFA sebesar 0.064\%. Apabila dianalisis secara parsial, buah busuk dan atau janjang kosong(empty bunch)adalah mutu buah yang memiliki pengaruh terbesar dalam peningkatan kandungan FFA dalam CPO. Setidaknya ada dua hal yang menyebabkan munculnya empty bunch, pertama terpanennya empty buncholeh pemanen dan kemudian diangkut truk buah hingga ke loading ramp PKS.

Kedua adalah karena buah yang dipanen tidak dapat segera diolah pada hari yang sama (terlambat angkut) sehingga mengalami penundaan olah atau penimbunan baik di kebun maupun di loading ramp PKS. Peristiwa terpanen dan terangkutnya empty bunch hingga ke PKS terjadi karena rotasi panen yang tinggi $(\geq 6 / 9)$ sehingga buah matang pada tanaman kelapa sawit telahberubah menjadi over ripe dan empty bunch, tergantung umur kematangan buah.Rotasi panen yang tinggi dapat meningkatkan produksi buah dengan kematangan yang buruk atau terlalu tua bahkan sampai mengalami pembusukan. Setiap kenaikan persentase blok dengan rotasi tinggi 1\% akan menyebabkan peningkatkan persentase buah busuk $0.33 \%$ (Djoharet al.2003).

Kenaikan FFA dalam CPO Akibat Buah Luka. Luka buah dapat timbul karena penanganan buah (panen dan pasca panen) yang kasar; kontaminasi patogen (buah sakit); dan kerusakan struktur buah karena hama tikus. Luka pada buah yang diiringi pembentukan FFA berasal dari pelukaan selama pengumpulan dan pengangkutan ke PKS atau buah membusuk (Mangoensoekarjo dan Semangun 2003). Hartley (1967) juga menyatakan bahwa proses panen, pengangkutan ke PKS sampai dengan pergerakan buah di dalam PKS adalah sumber buah memar atau luka yang dapat meningkatkan kandungan FFA dalam CPO.

Pembentukan FFA dalam buah dimulai dengan pecahnya dinding sel yang mengandung minyak, sehingga enzim lipolitik yang terdapat pada protoplasma bekerja menghidrolisis lemak dan asam lemak akhirnya dibebaskan (FFA terbentuk). Reaksi tersebut akan berlangsung sangatcepat, akan tetapi pada buah yang tidak luka
FFA hanya naik $0.2 \%$ selama 4 hari (Mangoensoekarjo dan Semangun 2003). Enzim lipolitik akan diinaktifkan pada suhu $60^{\circ} \mathrm{C}$ sewaktu perebusan buah di PKS,dengan begitu dapat dikatakan bahwa proses pengumpulan dan pengangkutan buah di kebun atau sebelum diolah di PKS merupakan titik kritis timbulnya luka pada buah yang dapat mempercepat terbentuknya FFA di lapangan.

Penggunaan alat panen yang kurang bijak adalah salah satu penyebab buah luka karena penanganan panen yang kasar. Kelapa sawit yang semakin tinggi akan menyulitkan penggunaan dodos dalam menjangkau buah sehingga potensi adanya buah luka lebih besar. Ketinggian kelapa sawit tergantung pada tahun tanam, semakin tua maka semakin tinggi jangkauan panennya.

Umur tanaman berdasarkan tahun tanam di TSE 1 talah mencapai 6-8 tahun,yang berdampak pada sudut panen dengan dodos akan lebih kecil dari $45^{\circ}$. Penggunaan dodos dengan sudut $>45^{\circ}$ akan menguras tenaga pemanen yang bekerja selama 7 jam setiap harinya. Tenaga yang terkuras akan berdampak pada konsentrasi pemanen yang menurun sehingga potensi pelukaan buah karena terkena pisau dodos lebih besar. Penggunaan egrek atau sabit sebagai alat panen dengan kondisi seperti ini adalah pilihan yang lebih bijak bila diterapkan. Salat satu tujuannya adalah memudahkan tenaga panen dalam memotong buah sekaligus meminimalisir adanya buah luka karena alat panen.

Buah luka juga diakibatkan karena buah yang busuk atau sakit. Buah sakit disebabkan karena aktivitas mikroorganisme seperti bakteri dan cendawan. Salah satu penyakit tanaman kelapa sawit adalah busuk tandan yang disebabkan oleh cendawan Marasmius palmivorius. Tandan buah yang terserang berat oleh penyakit ini dapat meningkatkan FFA dalam minyak (Pahan 2006). Secara perlahan aktivitas bakteri dan cendawan mengakibatkan kerusakan pada minyak dalam buah, salah satunya kenaikan kadar FFA dalam minyak melalui reaksi oksidasi (Mangoensoekarjo dan Semangun 2003). Tingkat serangan penyakit busuk tandan di Kebun Talisayan 1 relatif rendah atau tidak membahayakan secara ekonomis.

Buah rusak atau buah tidak utuh dapat disebabkan salah satunya oleh serangan hama tikus. Serangan tikus (Rathus tiomanicus)dewasa adalah dengan mengonsumsidaging buah (mesocarp)antara5.94-13.70 gramhari $^{-1}$ ekor $^{-1}$ atau setara dengan kehilangan minyak (CPO) berkisar antara 327.96-962.38 $\mathrm{kg} \mathrm{ha}^{-1}$ per tahun (Sipayung dan Thohari 1994). Serangan hama ini sudah pasti 
akan merusak dinding sel buah yang selanjutnya akan memicu terjadinya reaksi hidrolisis dan oksidasi yang merugikan, akan tetapi di Kebun Talisayan 1 serangan hama tikus bukan menjadi prioritas utama atau masih dalam toleransi sehingga pengendalian hayati dengan burung hantu terbilang efektif. Penanganan yang diperlukan dalam mengendalikan aktivitas OPT (Organisme Pengganggu Tanaman) setidaknya dengan melakukan pemeliharaan sanitasi lingkungan tanaman kelapa sawit dan merawat tanaman sehingga terhindar dari serangan hama dan penyakit yang merusak buah (Mangoensoekarjo dan Semangun 2003).

\section{Penurunan Rendemen CPO karena Dampak Mutu Buah dan Kehilangan Hasil Panen}

Dua penyebab rendahnya rendemen CPO yakni mutu buah olahan yang buruk dan kehilangan hasil panen. Mutu buah buruk yang diprediksi menyebabkan rendemen CPOrendah adalah buah mentah (unripe), buah lewat matang (over ripe), buah busuk dan atau janjang kosong (empty bunch), buah abnormal dan buah bergagang panjang (long stalk). Kecuali kelompok buah bergagang panjang semua kelompok mutu buah buruk memberikan pengaruh yang signifikan terhadap penurunan rendemen minyak. Hubungan antara pengolahan buah bermutu buruk denganrendemen CPO dapat dilihat pada Tabel 2.

Kelompok empty bunchdan abnormal adalah dua kelompok mutu buah buruk yang pengaruhnya paling besar terhadap penurunan rendemen minyak daripada kelompok mutu buah buruk lainnya. Kelompok empty bunch adalah kelompok buah yang telah hampir $90 \%$ brondolannya telah lepas dari tandan atau telah terserang penyakit, artinya pengolahan buah empty bunch hanya akan menambah tonase TBS tanpa menghasilkan tambahan rendemen minyak karena tandan kosong tidaklah menghasilkan minyak.

Tabel 2. Hubungan presentase produksi buah bermutu buruk (buah mentah, buah lewat matang, janjang kosong dan buah busuk, serta buah abnormal) bulanan dengan rataan rendemen CPO pada Januari 2012-April 2013

\begin{tabular}{|c|c|c|c|c|c|}
\hline Bulan & $\mathrm{BM}(\%)$ & BLM (\%) & $\mathrm{JJK}(\%)$ & Abnormal (\%) & Rendemen $(\%)$ \\
\hline Januari 12 & $3.85 \pm 1.76$ & $15.56 \pm 5.98$ & $1.11 \pm 0.99$ & $9.15 \pm 2.10$ & $25.06 \pm 0.56$ \\
\hline Februari 12 & $5.01 \pm 1.67$ & $17.24 \pm 5.77$ & $1.10 \pm 0.73$ & $9.37 \pm 2.90$ & $24.75 \pm 0.51$ \\
\hline Maret 12 & $2.95 \pm 1.63$ & $28.89 \pm 11.42$ & $4.69 \pm 4.25$ & $9.22 \pm 2.63$ & $23.69 \pm 0.47$ \\
\hline April 12 & $5.17 \pm 2.03$ & $19.81 \pm 6.65$ & $3.06 \pm 3.63$ & $10.89 \pm 3.77$ & $23.95 \pm 0.37$ \\
\hline Mei 12 & $6.87 \pm 2.36$ & $14.02 \pm 5.74$ & $2.02 \pm 2.68$ & $14.97 \pm 5.27$ & $23.36 \pm 0.45$ \\
\hline Juni 12 & $6.04 \pm 2.91$ & $8.44 \pm 4.12$ & $0.87 \pm 0.70$ & $17.99 \pm 8.51$ & $23.00 \pm 0.50$ \\
\hline Juli 12 & $5.34 \pm 2.31$ & $7.60 \pm 3.19$ & $0.92 \pm 0.61$ & $24.80 \pm 11.63$ & $22.27 \pm 0.95$ \\
\hline Agustus 12 & $1.78 \pm 19.3$ & $6.18 \pm 4.47$ & $1.21 \pm 1.01$ & $23.52 \pm 0.59$ & $23.52 \pm 0.59$ \\
\hline Septemeber 12 & $5.00 \pm 2.65$ & $13.35 \pm 7.48$ & $4.30 \pm 3.49$ & $29.26 \pm 14.88$ & $21.94 \pm 0.67$ \\
\hline Oktober 12 & $6.37 \pm 3.22$ & $6.33 \pm 3.40$ & $1.04 \pm 0.64$ & $27.11 \pm 13.16$ & $23.01 \pm 0.10$ \\
\hline November 12 & $4.04 \pm 2.09$ & $9.36 \pm 5.35$ & $2.32 \pm 1.58$ & $18.81 \pm 10.04$ & $22.84 \pm 0.20$ \\
\hline Desember 12 & $5.44 \pm 2.94$ & $12.68 \pm 6.95$ & $2.61 \pm 2.01$ & $15.79 \pm 9.23$ & $23.33 \pm 0.27$ \\
\hline Januari 13 & $4.49 \pm 2.69$ & $17.62 \pm 10.43$ & $5.11 \pm 4.77$ & $12.45 \pm 8.60$ & $22.26 \pm 4.37$ \\
\hline Februari 13 & $4.03 \pm 2.71$ & $16.83 \pm 11.99$ & $7.68 \pm 7.64$ & $9.72 \pm 8.42$ & $21.50 \pm 4.31$ \\
\hline Maret 13 & $4.37 \pm 2.95$ & $15.09 \pm 9.65$ & $7.20 \pm 6.72$ & $8.92 \pm 8.05$ & $22.37 \pm 4.49$ \\
\hline April 13 & $5.93 \pm 3.57$ & $15.80 \pm 8.01$ & $4.88 \pm 4.61$ & $9.25 \pm 4.50$ & $23.61 \pm 0.47$ \\
\hline Persamaan regresi linier & \multicolumn{5}{|c|}{ Rendemen $(\%)=25.4-0.07 \mathrm{BM}+0.05 \mathrm{BLM}-0.41 \mathrm{JJK}-0.08$ abnormal } \\
\hline $\mathrm{R}^{2}$ & \multicolumn{3}{|c|}{$82.4 \%$} & & \\
\hline
\end{tabular}

Sumber : Laboratorium Talisayan Mill (TSM)

Keterangan : BM (buah mentah), BLM (buah lewat matang), JJK (janjang kosong dan buah busuk) 
Buah abnormal adalah kelompok buah yang memiliki fruit set yeng rendah atau jumlah buah partenokarpinya lebih banyak daripada buah yang jadi. Buah partenokarpi atau buah tidak sempurna disebabkan karena penyerbukan tidak sempurna atau tidak dapat dilakukan karena posisi buah yang terjepit oleh pelepah, sehingga menghasilkan buah dengan kandungan minyak yang rendah serta tidak memiliki cangkang dan endosperm (Prasetyo dan Susanto 2005).

Penurunan rendemen $\mathrm{CPO}$ secara signifikan disebabkan oleh pengolahan buah bermutu buruk secara bersamaan.Setiap pengolahan $1 \%$ buah bermutu buruk akan mengurangi rendemen minyak sebesar $0.14 \%$ (Tabel 2). Model persamaan regresi linier dapat $82.4 \%\left(R^{2}\right)$ menjelaskan secara tepat bahwa penurunan rendemen $\mathrm{CPO}$ disebabkan karena pengolahan buah bermutu buruk, sisanya $17.6 \%$ penurunan rendmen CPO disebabkan oleh faktor lain di luar model persamaan.

Kehilangan hasil produksi juga dapat menjadi faktor penurunan rendemen CPO, yaitu buah lepas tidak dikutip, restan (terlambat pengangkutan), dan buah matang tidak dipanen. Ketiga sumber kehilangan hasil tersebut dapat terjadi saat di kebun ataupun pengangkutan. Buah tinggal atau buah matang yang tertinggal di pokok adalah tanggung jawab pemanen dan mandor panen, apabila supervisi berjalan dengan baik maka perilaku pemanen yang demikian dapat dicegah. Pengutipan buah lepas yang baik mencirikan kualitas SDM yang baik pula. Mengutip buah lepas dari dalam blok dan disusun rapi dengan alas karung di TPH adalah tugas pemanen, sedangkan mengangkut buah lepas dari TPH ke PKS adalah tugas dari kenek buah, sehingga penting fungsi mandor panen dan mandor transpor untuk menjaga sikap disiplin kerja para anggotanya dalam mengutip dan mendistribusikan buah lepas secara optimal.

Sebab-sebab lain kehilangan hasil yang diamatai di lapangan antara lain: brondolan yang tercecer di pelepah; brondolah yang tercecer di TPH brondolan yang tercecer di jalan koleksi atau jalan utama saat pengangkutan; dan TBS yang terjatuh saat pengangkutan.

Salah satu solusi yang dapat dilakukan perusahaan dalam meminimalisir kehilangan hasil adalah menambah tenaga kerja untuk pengutipan brondolan dan memberikan pengawasan ketat saat pemuatan buah dari TPH ke truk agar tinggi tumpukan tidak terlalu tinggi. Pemahaman akan orientasi pekerjaan bukan hanya menguntungkan secara pribadi namun secara kolektif (pribadi dan perusahaan) penting untuk selalu ditanamkan oleh perusahaan.Dampak sikap pemanen atau kenek buah yang kurang disiplin mengutip buah lepas dan kurang baiknya supervisi akan menurunkan rendemen CPO sebesar 4\% (Mangoesoekarjo dan Tojib 2003). Perusahaan yang mengutamakan kualitas akan selalu menjaga komitmen dari tiap SDM atau karyawan yang bekerja melalui pembinaan secara rutin dan terus-menerus agar menjadi perusahaan yang prestatif dan memiliki kualitas SDM yang baik.

\section{Kenaikan FFA dalam CPO karena Dampak Restan dan Pengangkutan Buah}

Restan disebabkan oleh pengangkutan buah yang terlambat. Keterlambatan tersebut terjadi karena jalan dan atau jembatan tidak dapat dilalui truk buah (dump truck) serta waktu pengangkutan buah yang kurang efektif. Kondisi jalan yang tidak dapat dilalui truk buah dipengaruhi oleh faktor alam, yaitu curah hujan tinggi. Curah hujan optimum (2000 mm tahun $\left.{ }^{-1}\right)$ sebagai syarat petumbuhan kelapa sawit (Hartley 1967) telah dipenuhi di Talisayan 1 Estate (TSE 1), bersamaan dengan hal tersebut pengelola kebun yang belum siap menjadikan jalan dan jembatan yang cocok dengan berbagai cuaca (all weather road) akan berpeluang lebih besar memproduksi buah restan.

Besarnya pengaruh restan bervariasi bergantung dari umur buah restan, semakin lama buah terlambat angkut atau tertimbun akan semakin memperburuk mutu buah sekaligus meningkatkan kandungan FFA dalam CPO. Berikut adalah hasil uji laboratorium berbagai umur restan dengan kenaikan FFA (Tabel 3).

Koefisien regresi 0.94 mengandung pengertian bahwa setiap umur restan bertambah 1 hari (24 jam), maka FFA akan meningkat sebesar $0.94 \%$. Model ini memiliki nilai $\mathrm{R}^{2} 85.4 \%$, artinya $84.5 \%$ kenaikan FFA hampir tepat disebabkan oleh umur restan dan $15.5 \%$ penyebab sisanya tidak dijelaskan pada model persamaan ini. Kanaikan FFA dalam model ini berlaku untuk buah masak yang terlambat angkut, karena $\geq 98 \%$ target panen adalah buah masak. Kriteria buah masak berdasarkan kebijakan perusahaan adalah buah telah membrondol satu buah.

Kenaikan kandungan FFA akan bervariasi apabila buah restan berasal dari buah mentah atau lewat masak, oleh karenanya penting menyesuaikan faktor cuaca dengan prasarana kebun sehingga dapat menekan restan.Kebun Talisayan 1 memiliki topografi yang datar sehingga faktor kemiringan lereng tidak menjadi masalah yang berarti dan tidak pula berpotensi menambah produksi restan. Akan tetapi, salah satu kebun yang mengolah buahnya di TSM 
adalah Biatan Estate (BTE). BTE memiliki kemiringan lahan dengan lereng berbukit atau topografi yang curam sehingga apabila kondisi ini dikombinasikan dengan cuaca yang bercurah hujan tinggi, maka secara langsung akan menambah jumlah buah restan (Djohar et al. 2003). Restan dapat menurunkan kualitas fraksi atau mutu buah karenaterjadinya penundaan pengolahan buah baik di TPH maupun di loading ramp PKS (Hidayat 2009).

Tabel 3. Pengaruh umur restan terhadap kandungan FFA dalam CPO

\begin{tabular}{|c|c|c|c|c|c|c|}
\hline \multirow{3}{*}{ Umur restan (hari) } & \multicolumn{3}{|c|}{ FFA (\%) } & \multirow{2}{*}{\multicolumn{3}{|c|}{ Rataan FFA (\%) }} \\
\hline & \multicolumn{3}{|c|}{ Ulangan } & & & \\
\hline & 1 & 2 & 3 & & & \\
\hline 0 & 1.92 & 1.66 & - & 1.79 & \pm & 0.18 \\
\hline 1 & 2.25 & 2.25 & 2.37 & 2.29 & \pm & 0.07 \\
\hline 2 & 3.75 & 2.55 & - & 3.15 & \pm & 0.85 \\
\hline 3 & 7.53 & - & - & 7.35 & \pm & 0.00 \\
\hline 4 & 9.29 & 6.27 & 8.96 & 8.17 & \pm & 1.66 \\
\hline 5 & 6.78 & 9.89 & 10.73 & 9.13 & \pm & 2.08 \\
\hline 6 & 7.55 & 8.22 & 13.54 & 9.77 & \pm & 3.28 \\
\hline 7 & 10.51 & 9.15 & 8.14 & 9.27 & \pm & 1.19 \\
\hline 8 & 16.89 & 17.13 & 10.43 & 14.82 & \pm & 3.80 \\
\hline 9 & - & - & - & & - & \\
\hline 10 & 10.84 & 10.60 & 9.68 & 10.37 & \pm & 0.61 \\
\hline 11 & 13.75 & 9.95 & 13.13 & 12.28 & \pm & 2.04 \\
\hline 12 & 16.54 & 15.80 & 13.70 & 15.35 & \pm & 1.47 \\
\hline 13 & 11.89 & 11.43 & 18.64 & 13.99 & \pm & 4.04 \\
\hline 14 & 9.78 & 18.66 & 18.56 & 15.67 & \pm & 5.10 \\
\hline
\end{tabular}

Persamaan regresi linier

FFA $(\%)=3.079+0.94$ Umur restan

$\mathrm{R}^{2}$

$84.1 \%$

Sumber : Data primer uji laboratorium PKS TSM

Waktu pengangkutan berhubungan dengan waktu simpan buah di bak truk dan berkorelasi positif pada suhu dalam bak. Kombinasi waktu simpan dan kenaikan suhu (menjadi suhu kamar) akan menurunkan mutu minyak yang terkandung dalam buah. Salah satu pemicunya adalah aktivitas oksidasi yang terjadi pada suhu tinggi. Oksidasi akan mengakumulasi peroksida sebagai penyebab kerusakan utama minyak (ketengikan) karena minyak dibiarkan di udara dan semakin bertambah dengan kenaikan suhu (Ketaren 1986). Oksidasi menjadikan trigliserida tak jenuh berikatan dengan oksigen di udara sehingga menghasilkan senyawa aldehida dan keton. Kedua senyawa ini tidak disukai karena menyebabkan ketengikan (Pahan 2006).Ketengikan diartikan sebagai kerusakan atau perubahan bau dan rasa dalam lemak atau bahan pangan berlemak seperti CPO (Ketaren 1986).

Kerusakan ini tidak berdampak signifikan karena terjadi secara perlahan, namun semakin besar apabila buah telah mengalami pelukaan. Suhu kamar juga memberikan lingkungan yang sesuai bagi perkembangan mikroorganisme yang bersifat kontaminan dan mempercepat pembusukan buah. Aktivitas mikroorganisme (bakteri dan cendawan) juga dipicu dari kotoran seperti tanah dan serasah dari kebun yang terikut bersama buah lepas. Kedua aktivitas ini dapat meningkatkan kandungan FFA dalam CPO bahkan penyebab bau tengik, perubahan warna minyak, penurunan kandungan vitamin dan asam lemak esensial (Pahan 2006). Usaha menekan agar waktu selama proses panen sampai sterilisasi di PKS sesingkat mungkin dilakukan dalam rangka memproduksi CPO dengan kandungan FFA rendah (Hartley 1967).

Banyaknya tempat pengumpulan hasil (TPH) liar atau TPH berjumlah di atas standar $(\geq$ 1.4 TPHha $^{-1}$ ) dapat memperpanjang waktu pengangkutan. Efektivitas pengangkutan buah dilihat dari semakin singkatnya waktu yang dihabiskan untuk pengangkutan buah dari TPH ke loading ramp PKS. Semakin lambat pengumpulan buah baik dari TPH ke loading ramp PKS dapat menjadi faktor yang mempercepat pembentukkan FFA (Hidayat 2009). Kebijakan perusahaan yang tidak membatasi jam kerja karyawan ( $>7$ jam) kenek muat buah, sebetulnya dapat meminimalisir jumlah buah restan. Apabila situasi tersebut dioptimalkan denganbaik, efektivitas waktu 
pengangkutan dapat meningkatkan kualitas FFA sekaligus meningkatkan prestasi kerja dan penghasilan kenek buah apabila dapat dilaksanakan dengan baik dan efektif. Dengan begitu memelihara kondisi kebersihan TPHdan jumlah TPH sesuai dengan standar yang telah ditetapkan adalah salah satu cara penghematan waktu angkut buah (efektivitas pengangkutan buah) dalam rangka menekan FFA serendah mungkin (Mangoensoekarjo dan Semangun 2003).

\section{KESIMPULAN}

Mutu produksi dilihat dari terpenuhinya rendemen CPO minimal sesuai standar perusahaan (23-24\%) dan kandungan FFA dalam $\mathrm{CPO}<3 \%$, sehingga penting mengetahui dan memperlajari faktor-faktor penyebabnya. Kelompok mutu buah buruk yang terpanen dan diolah di PKS (pabrik pengolahan kelapa sawit) dapat meningkatkan kandungan FFA sekaligus menurunkan rendemen CPO olahan. Besarnya peningkatan kandungan FFA dalam CPO adalah $0.04 \%$ jika terdapat $1 \%$ buah bermutu buruk (buah mentah, buah lewat matang, janjang kosong dan buah busuk, serta buah abnormal) yang terdapat pada seluruh TBS yang diolah. Penurunan rendemen CPO adalah sebesar $0.14 \%$ jika terdapat $1 \%$ buah bermutu buruk yang terdapat pada seluruh TBS yang diolah. Mutu buah yang buruk dipengaruhi oleh lamanya penundaan buah untuk diolah (restan), baik saat buah berada padapokok kelapa sawit, di tempat pengumpulan hasil (TPH), di loading ramp PKS, maupunakibat pelukaan pada buah. Semakin lama penundaan buah untuk diolah dan banyaknya luka pada buah akan semakin memperburuk mutu buah. Lamanya penundaan buah dapat meningkatkan kandungan FFA CPO sebesar $0.94 \%$ setiap bertambahnya umur tunda 1 hari (24 jam).

Kedisiplinan kerja karyawan panen dan tim supervisi menjadi catatan penting bagi perusahaan karena dapat mempengaruhi mutu produksi kelapa sawit. Kualitas sarana dan prasarana seperti jalan, jembatan dan jumlah truk pengangkut buah harus selalu dalam keadaan baik untuk menjaga kualitas CPO.

\section{DAFTAR PUSTAKA}

Djohar, S., Tanjung, H., Cahyadi, E.R. 2003. Building a Competitive Advantage on CPO through Supply Chain Management: A Case Study in PT. Eka Dura Indonesia, Astra Agro Lestari, Riau. JMA.1(1):20-23.

Hartley, C.W.S. 1967. The Palm Oil (Elaeis guineensis Jacq.). London (GB): Longman Group Limited.

Hidayat, M.A. 2009. Analisis konsistensi mutu dan rendemen crude palm oil (CPO) di pabrik kelapa sawit Tanjung Seumantoh PTPN I Nanggroe Aceh Darussalam skripsi. Sumatera Utara (ID): Universitas Sumatera Utara.

Ketaren, S. 1986. Pengantar Teknologi Minyak dan Lemak Pangan. Jakarta (ID): Penerbit UI Pr.

Mangoensoekarjo, S., Semangun, H. 2003. Manajemen Agrobisnis Kelapa Sawit. Mangoensoekarjo S, Tojib A.T, editor. Yogyakarta (ID). Gajah Mada University Pr.

Pahan, I. 2006. Panduan Lengkap Kelapa Sawit. Jakarta (ID): Penebar Swadaya.

Presetyo, A.E., Susanto, A. 2005. Fruits set kelapa sawit dengan teknik hatch-carry Elaedobius kamerunicus [ulasan]. Medan (ID): Pusat Penelitian Kelapa Sawit.

Sipayung, A., Thohari, M. 1994. Penelitian pengembangan burung hantu Tytoalba dalam perkebunan kelapa sawit. Buletin PPKS.1:97-104.

Wahyudi, A. 2012. Produksi CPO Indonesia Terbesar di Dunia [Internet]; [diunduh pada: 2013 Oktober 11] . Berita. Tersedia pada: http://www.bumn.go.id/ptpn8/ publikasi/berita/produksi-cpo-indonesiaterbesar-di-dunia/

Wiyono. 2013. Hasrat menguasai pasar minyak sawit. Info Sawit. 7(1):12-15. 